\title{
ANÁLISE TÉRMICA DE CONCRETOS COM INSERÇÃO DE RESÍDUOS RECICLADOS DE PNEUS INSERVÍVEIS
}

\author{
C. SIMONETTI ${ }^{1}$, A. M. GIL ${ }^{2}$, G. C. MANICA ${ }^{3}$, A. L. BAUER ${ }^{4}$, B. F. TUTIKIAN ${ }^{5}$ \\ ${ }^{1}$ Programa de Pós-Graduação em Engenharia Civil, UNISINOS, São Leopoldo, RS, Brasil. \\ ${ }^{2}$ Department of Civil and Environmental Engineering, Michigan State University, East Lansing, EUA. \\ 3 itt Performance, UNISINOS, São Leopoldo, RS, Brasil. \\ ${ }^{4}$ UNISINOS, São Leopoldo, RS, Brasil. \\ 5 itt Performance, UNISINOS, São Leopoldo, RS, Brasil
}

\begin{abstract}
RESUMO
Atualmente tem-se uma grande motivação de medidas mitigadoras dos impactos ambientais acerca da disposição incorreta de pneus inservíveis, bem como a realização de pesquisas sobre possíveis métodos de reaproveitamento destes elementos. Inserida nesse cenário está a construção civil, que pode empregar tecnologias visando a integração resíduos ao concreto com a perspectiva de qualificar algumas de suas propriedades e gerar benefícios para o meio ambiente. Neste contexto, o objetivo deste artigo é avaliar a não-combustibilidade de concretos elaborados com agregado reciclado de borracha e com fibras metálicas recicladas, ambos materiais oriundos de pneus inservíveis. O programa experimental compreendeu a caracterização dos materiais e a moldagem de corpos de prova de concretos com a substituição do agregado miúdo por agregado reciclado de borracha e com a inserção da fibra metálica reciclada. A substituição em relação ao volume de agregado miúdo ocorreu nos percentuais de 5,0\% e 10,0\%. A fibra de aço reciclada foi adicionada nos percentuais de $0,5 \%$ e $1,5 \%$, em volume. Para as dosagens, utilizou-se o traço 1:2,9:3,0, relação água/cimento de 0,53 e percentual fixo de $0,6 \%$ de aditivo superplastificante sobre a massa do cimento para todos os concretos confeccionados. A análise térmica consistiu na realização do ensaio de não-combustibilidade através da norma ISO 1182, e da caracterização térmica da borracha reciclada através de ensaios de TGA, DTGA, DSC e DTA. Em relação à não-combustibilidade, o concreto convencional foi classificado como não combustível, conforme esperado. Ao ensaiar os concretos com a inserção de fibra metálica ou partículas de borracha de pneus inservíveis, houve a inflamação de chamas na superfície destes concretos, caracterizando as amostras como combustíveis. Como considerações finais, para os materiais classificados como combustíveis, faz-se necessário realizar outros ensaios visando avaliar propriedades específicas de liberação de calor, fumaça e propagação de chamas. Desta forma, o concreto com a utilização borracha e da fibra metálica recicladas de pneus inservíveis também devem ser ensaiados frente aos parâmetros de resistência ao fogo.
\end{abstract}

Palavras clave: pneus inservíveis; concreto; caracterização térmica, reação ao fogo. 


\section{INTRODUÇÃO}

Nas últimas décadas, o meio técnico e acadêmico tem empregado esforços para desenvolver materiais alternativos com menor impacto ambiental, bem como menor consumo de recursos naturais (SILVA JÚNIOR, 2014). Dentro deste contexto, se observa maior espaço para o uso de materiais reciclados de pneus descartados, uma vez que a disposição inadequada destes elementos pode gerar graves problemas ambientais devido a sua lenta decomposição, poluição ambiental e dificuldade de armazenamento (PINTO et al., 2017).

Pesquisas tem mostrado resultados positivos quanto a incorporação da borracha e da fibra metálica recicladas de pneus inservíveis na matriz do concreto, uma vez que permite modificações das propriedades do concreto para atendimento a requisitos específicos em que as propriedades destes resíduos são relevantes. No entanto, ainda persiste uma lacuna em relação ao desempenho e classificação do concreto com a utilização borracha e da fibra metálica recicladas de pneus inservíveis frente a elevadas temperaturas.

A classificação dos materiais utilizados na construção civil é dada pela Tabela 3 da norma brasileira NBR 16626 (ABNT, 2017), e pode ser observada na Tabela 1. A norma brasileira mencionada estabelece as condições a serem atendidas pelos materiais de acabamento e de revestimento empregados nas edificações.

Tabela 1. Classificação de produtos de construção em geral (vide exceções).

\begin{tabular}{|c|c|c|c|c|}
\hline \multirow{2}{*}{\multicolumn{2}{|c|}{ Classe }} & \multicolumn{3}{|c|}{ Método de ensaio } \\
\hline & & $\begin{array}{c}\text { ISO } 1182 \text { (ISO, } \\
2010)\end{array}$ & $\begin{array}{c}\text { NBR } 9442 \text { (ABNT, } \\
\text { 1988) }\end{array}$ & $\begin{array}{c}\text { ASTM E } 662 \text { (ASTM, } \\
2018)\end{array}$ \\
\hline \multicolumn{2}{|c|}{ I } & $\begin{array}{c}\text { Incombustível } \\
\Delta \mathrm{t} \leq 30^{\circ} \mathrm{C} \\
\Delta \mathrm{m} \leq 50 \% \\
\mathrm{t}_{\mathrm{f}} \leq 10 \mathrm{~s}\end{array}$ & - & - \\
\hline \multirow{2}{*}{ II } & $\mathrm{A}$ & Combustível & $1 p \leq 25$ & $\mathrm{Dm} \leq 450$ \\
\hline & $\mathrm{B}$ & Combustível & $1 p \leq 25$ & $\mathrm{Dm}>450$ \\
\hline \multirow{2}{*}{ III } & $\mathrm{A}$ & Combustível & $25<1 \mathrm{p} \leq 75$ & $\mathrm{Dm} \leq 450$ \\
\hline & $\mathrm{B}$ & Combustível & $25<1 \mathrm{p} \leq 75$ & $\mathrm{Dm}>450$ \\
\hline \multirow{2}{*}{ IV } & $\mathrm{A}$ & Combustível & $75<1 \mathrm{p} \leq 150$ & $\mathrm{Dm} \leq 450$ \\
\hline & $\mathrm{B}$ & Combustível & $75<1 \mathrm{p} \leq 150$ & $\mathrm{Dm}>450$ \\
\hline \multirow{2}{*}{$\mathrm{V}$} & $\mathrm{A}$ & Combustível & $150<1 \mathrm{l} \leq 400$ & $\mathrm{Dm} \leq 450$ \\
\hline & $\mathrm{B}$ & Combustível & $150<\operatorname{lp} \leq 400$ & $\mathrm{Dm}>450$ \\
\hline \multicolumn{2}{|c|}{ VI } & - & $1 p>400$ & - \\
\hline
\end{tabular}

Fonte: adaptado de NBR 16626 (ABNT, 2017).

No âmbito da reação ao fogo, que tem como objetivo avaliar como os materiais reagem às elevadas temperaturas no princípio de um incêndio, a primeira etapa é determinar se o produto em questão é combustível ou não-combustível como forma de determinar a sua possível contribuição ao crescimento do incêndio. Caso seja classificado como incombustível, é possível afirmar que sua exposição à elevadas temperaturas não ocasiona perda de massa, liberação de energia e sustentação de chamas. Por outro lado, caso seja considerado combustível, o material ainda pode ser empregado em edificações desde que atenda a parâmetros específicos em ensaios que simulam condições reais de princípio de incêndio. 
Mitidieri e Loshimoto (1998) classificam o concreto e o aço, devido a sua natureza, como materiais não-combustíveis. No entanto, é necessário considerar que, quando a estes materiais são agregados outros, combustíveis ou com características desconhecidas, obtém-se um novo produto, que deve ser avaliado quanto ao seu desempenho ao fogo (ONO, 2007). Sendo assim, apesar de o concreto ser um material conhecidamente não-combustível, quando em sua matriz for incorporada outros materiais de propriedades desconhecidas, faz-se necessária uma nova avaliação para determinar o desempenho do material.

Desta forma, o objetivo deste artigo é avaliar a não-combustibilidade de concretos elaborados com agregado reciclado de borracha e com fibras metálicas recicladas, ambos materiais oriundos de pneus inservíveis. Ainda, faz parte do objetivo a avaliação termogravimétrica da borracha reciclada.

\section{METODOLOGIA}

\subsection{Estratégia de pesquisa}

Como estratégia de pesquisa adotada, o primeiro passo consistiu na caracterização dos materiais utilizados para moldagem das amostras. Em sequência foram realizados os ensaios de nãocombustibilidade conforme a ISO 1182 (ISO, 2010) sobre os concretos moldados, e foram realizados os ensaios térmicos acerca da borracha reciclada utilizada nas moldagens.

Nesta pesquisa foram elaborados concretos com substituição de agregado miúdo por agregado de borracha reciclada, nos percentuais de $5 \%$ e $10 \%$ de substituição em volume, e concretos com inserção de fibra metálica reciclada nos percentuais de $0,5 \%$ e $1,5 \%$ em volume. Também foi elaborado concreto convencional, como referência. Os concretos foram dosados com base no traço desenvolvido por Pacheco (2016), com proporção de 1:2,9:3,0 e relação água/cimento de 0,53.

\subsection{Caracterização dos materiais}

\subsubsection{Cimento, água e aditivo}

O cimento utilizado para a confecção dos concretos foi o tipo CP-IV 32. Foi realizada granulometria a laser no Laboratório de Caracterização e Valorização de Materiais da Universidade do Vale do Rio dos Sinos (Unisinos), utilizando como fluído o álcool isopropílico e o equipamento Microtrac, modelo

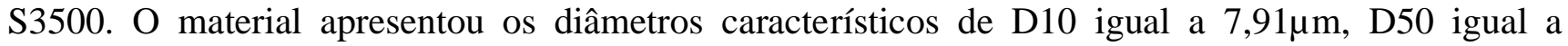

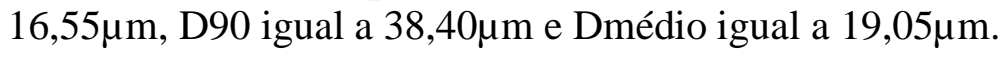

A água utilizada na moldagem das amostras foi do abastecimento da rede pública através do Serviço Municipal de Água e Esgotos de São Leopoldo - RS. O aditivo empregado é do tipo superplastificante sintético baseado na tecnologia de polímeros policarboxilatos, sendo utilizado um percentual fixo de $0,6 \%$ sobre a massa do cimento em todos os concretos confeccionados. Encontra-se no estado líquido, cor marrom e possui densidade de $1,09 \mathrm{~g} / \mathrm{cm}^{3}$.

\subsubsection{Agregado miúdo}

O agregado miúdo utilizado foi a areia dragada do Rio Jacuí, de origem quartzosa. As características físicas do agregado miúdo são apresentadas na Tabela 2. 
Tabela 2. Características físicas do agregado miúdo.

\begin{tabular}{|c|c|c|}
\hline Ensaio realizado & Resultado & Norma para ensaio \\
\hline Diâmetro máximo característico & $4,75 \mathrm{~mm}$ & $\begin{array}{c}\text { NBR NM 248 } \\
\text { (ABNT, 2003) }\end{array}$ \\
\hline Módulo de finura & 1,55 & $\begin{array}{c}\text { NBR NM 248 } \\
\text { (ABNT, 2003) }\end{array}$ \\
\hline Massa unitária & $1,49 \mathrm{~g} / \mathrm{cm}^{3}$ & $\begin{array}{c}\text { NBR NM 45 } \\
\text { (ABNT, 2006) }\end{array}$ \\
\hline Massa específica aparente & $2,61 \mathrm{~g} / \mathrm{cm}^{3}$ & $\begin{array}{c}\text { NBR NM 52 } \\
\text { (ABNT, 2009) }\end{array}$ \\
\hline Massa específica do agregado seco & $2,59 \mathrm{~g} / \mathrm{cm}^{3}$ & $\begin{array}{c}\text { NBR NM 52 } \\
\text { (ABNT, 2009) }\end{array}$ \\
\hline Massa específica do agregado com superfície seca & $2,60 \mathrm{~g} / \mathrm{cm}^{3}$ & $\begin{array}{c}\text { NBR NM 52 } \\
\text { (ABNT, 2009) }\end{array}$ \\
\hline
\end{tabular}

\subsubsection{Agregado graúdo}

O agregado graúdo utilizado no estudo tem origem basáltica, sendo extraído de regiões próximas a Porto Alegre. As características físicas do agregado graúdo são apresentadas na Tabela 3.

Tabela 3. Características físicas do agregado graúdo.

\begin{tabular}{|c|c|c|}
\hline Ensaio realizado & Resultado & Norma para ensaio \\
\hline Diâmetro máximo característico & $25 \mathrm{~mm}$ & $\begin{array}{c}\text { NBR NM 248 } \\
\text { (ABNT, 2003) }\end{array}$ \\
\hline Módulo de finura & 7,15 & $\begin{array}{c}\text { NBR NM 248 } \\
\text { (ABNT, 2003) }\end{array}$ \\
\hline Massa unitária & $1,52 \mathrm{~g} / \mathrm{cm}^{3}$ & $\begin{array}{c}\text { NBR NM 45 } \\
\text { (ABNT, 2006) }\end{array}$ \\
\hline Massa específica aparente & $2,69 \mathrm{~g} / \mathrm{cm}^{3}$ & $\begin{array}{c}\text { NBR NM 53 } \\
\text { (ABNT, 2009b) }\end{array}$ \\
\hline Massa específica do agregado seco & $2,82 \mathrm{~g} / \mathrm{cm}^{3}$ & $\begin{array}{c}\text { NBR NM 53 } \\
\text { (ABNT, 2009b) }\end{array}$ \\
\hline Massa específica do agregado com superfície seca & $2,74 \mathrm{~g} / \mathrm{cm}^{3}$ & $\begin{array}{c}\text { NBR NM 53 } \\
\text { (ABNT, 2009b) }\end{array}$ \\
\hline
\end{tabular}

\subsubsection{Agregado reciclado de borracha}

O agregado reciclado de borracha (ARB) foi fornecido pela empresa INDIBA - Industrial Batistella de Artefatos de Borracha Ltda., de Nova Santa Rita - Rio Grande do Sul (RS), especializada na reciclagem de pneus e confecção de percintas para a indústria moveleira, borracha moída, solados e saltos a partir de pneus usados.

O material fornecido pela recicladora possui faixas granulométricas de 0,7 a $2 \mathrm{~mm}$ (

Figura 1 ¡Error! No se encuentra el origen de la referencia.). A caracterização deste material foi semelhante ao do agregado miúdo, sendo que a Tabela 4 introduz os resultados de propriedades físicas do ARB. Para determinação da massa específica optou-se pelo método dos frascos de Chapman, descrito pela extinta norma NBR 9776 (ABNT, 1988b), utilizando querosene devido a sua baixa massa específica $\left(0,786 \mathrm{~g} / \mathrm{cm}^{3}\right)$ que permite a total decantação do material suspenso. 


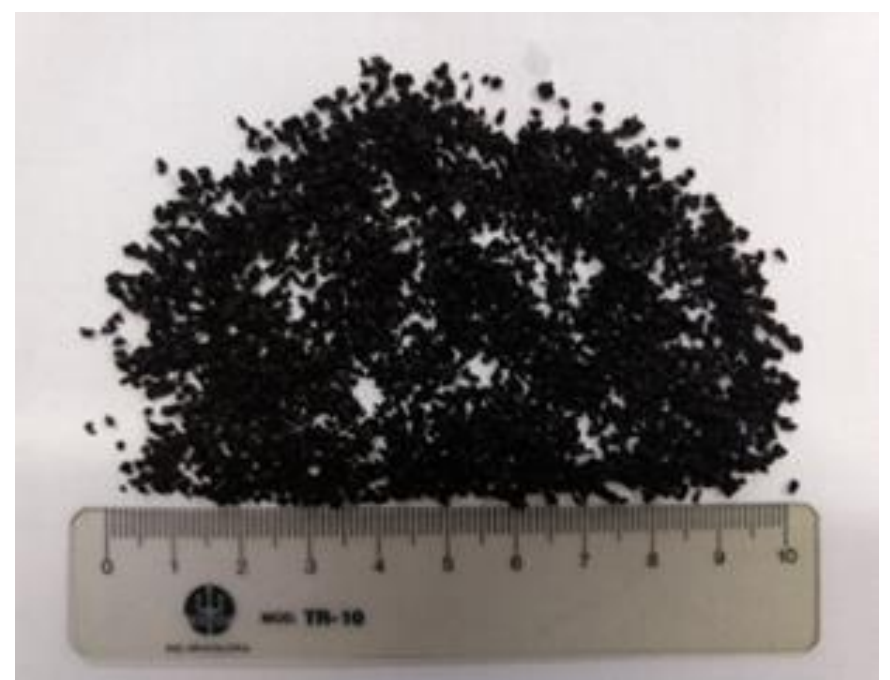

Figura 1. Amostra do agregado reciclado de borracha.

Tabela 4. Características físicas do ARB.

\begin{tabular}{|c|c|c|}
\hline Ensaio realizado & Resultado & Norma para ensaio \\
\hline Diâmetro máximo característico & $2,36 \mathrm{~mm}$ & $\begin{array}{c}\text { NBR NM 248 } \\
\text { (ABNT, 2003) }\end{array}$ \\
\hline Módulo de finura & 3,80 & $\begin{array}{c}\text { NBR NM 248 } \\
\text { (ABNT, 2003) }\end{array}$ \\
\hline Massa unitária & $0,54 \mathrm{~g} / \mathrm{cm}^{3}$ & $\begin{array}{c}\text { NBR NM 45 } \\
\text { (ABNT, 2006) }\end{array}$ \\
\hline Massa específica & $1,21 \mathrm{~g} / \mathrm{cm}^{3}$ & $\begin{array}{c}\text { NBR NM 52 } \\
(\text { ABNT, 2009) }\end{array}$ \\
\hline
\end{tabular}

\subsubsection{Fibra de aço reciclada}

As fibras metálicas utilizadas neste trabalho (Figura 2a) são fibras recicladas originadas de pneus inservíveis e que passaram por um processo de tratamento para remoção de partículas de borracha e outros resíduos. Também foram fornecidas pela empresa INDIBA - Industrial Batistella de Artefatos de Borracha Ltda., de Nova Santa Rita - RS.

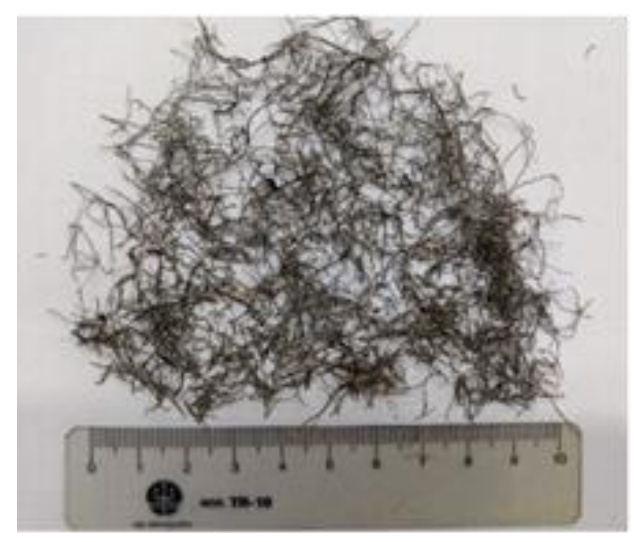

(a)

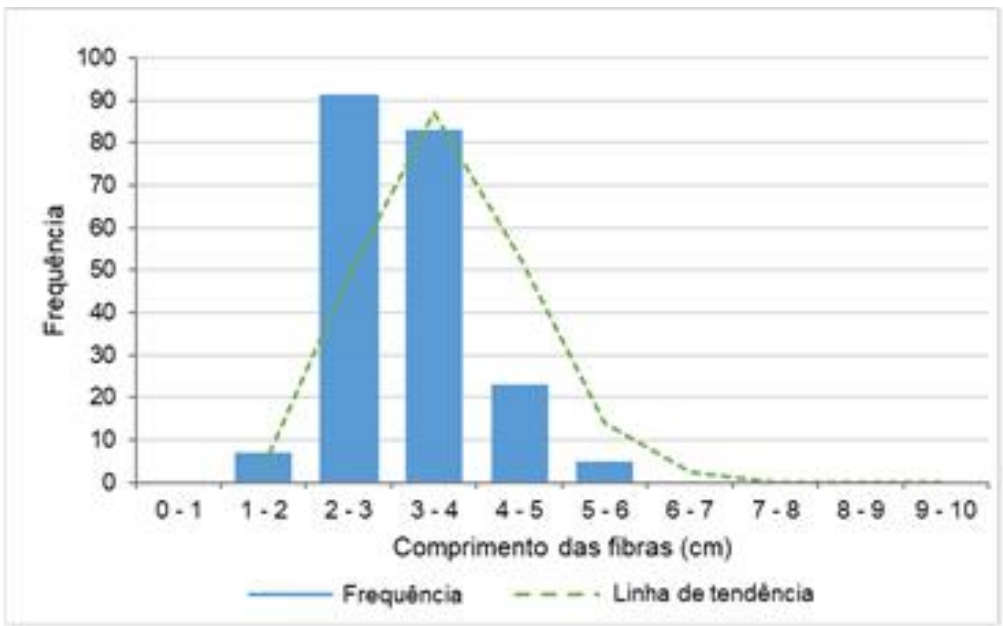

(b)

Figura 2. Amostra da fibra de aço reciclada (a) e distribuição das fibras de aço recicladas (b). 
As fibras recicladas utilizadas no estudo possuem diâmetro médio de $0,21 \mathrm{~mm}$ e comprimento médio de 31,50 mm. A Figura 2b mostra a distribuição, por comprimento, das fibras empregadas na pesquisa. Para determinar o comprimento médio das fibras foi utilizado o software Digimizer ${ }$. O diâmetro médio das fibras foi obtido através de medida unitária de cada elemento da amostra utilizando um paquímetro digital.

Antes de ser escaneada, a amostra passou por um processo de limpeza manual onde foram selecionadas apenas as fibras metálicas. Resíduos, como pequenas partículas de borracha ou náilon, foram descartados para que a análise fosse realizada exclusivamente sobre as fibras, sem interferência. Cabe ressaltar que este processo de limpeza fina não foi realizado sobre as fibras metálicas que foram inseridas no concreto. A Figura 3 apresenta duas imagens feitas das fibras (a) com a limpeza manual e (b) a imagem analisada pelo Digimizer®.

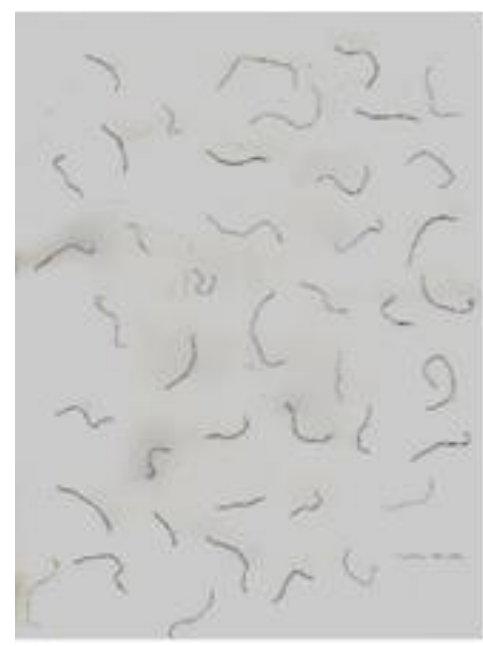

(a)

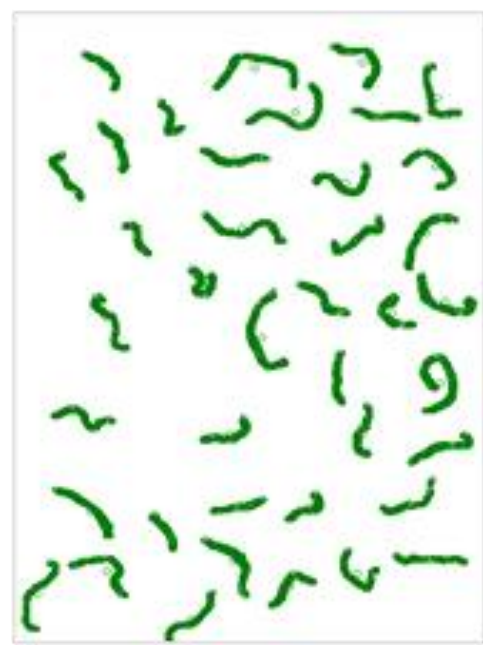

(b)

Figura 3. Imagem das fibras de aço (a) após limpeza manual e (b) escaneadas através do Digimizer®.

\subsection{Ensaio de não-combustibilidade}

As características de combustibilidade de materiais e produtos homogêneos é avaliado pela ISO 1182 (ISO, 2010), bem como de seus componentes, quando submetidos a uma temperatura normativamente definida de $750^{\circ} \mathrm{C}$. Verifica-se, nestas condições de exposição, a absorção e a liberação de calor, a ignição e sustentação de chamas e a perda de massa do material.

A ISO 1182 (ISO, 2010) prescreve a avaliação de no mínimo cinco amostras por tipo de material e classifica como incombustíveis aqueles materiais que apresentem:

a) desenvolvimento de calor muito limitado, não causando variação de mais de $30^{\circ} \mathrm{C}$ entre a temperatura máxima e a temperatura final do forno;

b) combustão sem chama ou com chamejamento durante tempo inferior a 10 segundos;

c) perda limitada de massa com variação inferior a $50 \%$.

\subsection{Análise térmica da borracha}

A análise térmica da borracha compreendeu os ensaios de TGA, DTGA, DSC e DTA aplicados sobre o resíduo de borracha reciclados de pneus inservíveis. Este ensaio foi realizado no Laboratório de Caracterização e Valorização de Materiais da Unisinos. Os dados obtidos através da análise térmica auxiliaram a identificar o comportamento da borracha reciclada quando inserida na matriz de concreto e submetidos ao ensaio experimental de não-combustibilidade. 


\section{RESULTADOS}

\subsection{Ensaio de não-combustibilidade}

Os resultados do ensaio de não-combustibilidade são apresentados nas Tabelas 5 a 7 com todos os dados coletados para as amostras analisadas. De acordo com a ISO 1182 (ISO, 2010), o concreto referência pode ser classificado como incombustível. Já os concretos com a inserção da borracha reciclada e da fibra metálica, independente do teor de inserção, são classificados como combustíveis.

Tabela 5. Ensaio de não-combustibilidade: REF.

\begin{tabular}{|c|c|c|c|}
\hline Amostra & $\begin{array}{c}\text { Variação da temperatura } \\
\text { do forno }\left({ }^{\circ} \mathbf{C}\right)\end{array}$ & $\begin{array}{c}\text { Perda de } \\
\text { massa }(\%)\end{array}$ & $\begin{array}{c}\text { Tempo de } \\
\text { ignição (s) }\end{array}$ \\
\hline 1 & 10,0 & 3,92 & 0,0 \\
\hline 2 & 4,5 & 3,36 & 0,0 \\
\hline 3 & 5,1 & 3,46 & 0,0 \\
\hline 4 & 7,4 & 3,22 & 0,0 \\
\hline 5 & 10,3 & 3,76 & 0,0 \\
\hline
\end{tabular}

Observando as Tabelas 6 e 7, nota-se que para todas as amostras de concretos com agregado reciclado de borracha e com inserção de fibra metálica, não foi constatada perda de massa superior a $50 \%$, nem variação na temperatura do forno maior que $30^{\circ} \mathrm{C}$.

Tabela 6. Ensaio de não-combustibilidade: BOR5\% e BOR10\%.

\begin{tabular}{|c|c|c|c|c|c|c|}
\hline \multirow{2}{*}{ Amostra } & \multicolumn{3}{|c|}{ BOR5\% } & \multicolumn{3}{c|}{ BOR10\% } \\
\cline { 2 - 7 } & $\begin{array}{c}\text { Variação da } \\
\text { temperatura } \\
\text { do forno }\left({ }^{\circ} \mathbf{C}\right)\end{array}$ & $\begin{array}{c}\text { Perda de } \\
\text { massa (\%) }\end{array}$ & $\begin{array}{c}\text { Tempo de } \\
\text { ignição }(\mathbf{s})\end{array}$ & $\begin{array}{c}\text { Variação da } \\
\text { temperatura } \\
\text { do forno }\left({ }^{\circ} \mathbf{C}\right)\end{array}$ & $\begin{array}{c}\text { Perda de } \\
\text { massa }(\%)\end{array}$ & $\begin{array}{c}\text { Tempo de } \\
\text { ignição } \\
(\mathbf{s})\end{array}$ \\
\hline 1 & 17,2 & 4,31 & 36,5 & 15,2 & 6,00 & 162,9 \\
\hline 2 & 6,2 & 4,88 & 45,3 & $*$ & 4,59 & 49,9 \\
\hline 3 & 6,4 & 4,40 & 33,9 & 8,0 & 4,37 & 58,7 \\
\hline 4 & 7,7 & 4,88 & 53,4 & 13,5 & 4,06 & 67,1 \\
\hline 5 & 8,9 & 4,99 & 41,8 & 10,0 & 4,79 & 89,6 \\
\hline
\end{tabular}

*Falha em termopar durante o ensaio.

Tabela 7. Ensaio de não-combustibilidade: FIB0,5\% e FIB1,5\%.

\begin{tabular}{|c|c|c|c|c|c|c|}
\hline \multirow{2}{*}{ Amostra } & \multicolumn{3}{|c|}{ FIB0,5\% } & \multicolumn{3}{c|}{ FIB1,5\% } \\
\cline { 2 - 7 } & $\begin{array}{c}\text { Variação da } \\
\text { temperatura } \\
\text { do forno }\left({ }^{\circ} \mathbf{C}\right)\end{array}$ & $\begin{array}{c}\text { Perda de } \\
\text { massa (\%) }\end{array}$ & $\begin{array}{c}\text { Tempo de } \\
\text { ignição (s) }\end{array}$ & $\begin{array}{c}\text { Variação da } \\
\text { temperatura } \\
\text { do forno }\left({ }^{\circ} \mathbf{C}\right)\end{array}$ & $\begin{array}{c}\text { Perda de } \\
\text { massa (\%) }\end{array}$ & $\begin{array}{c}\text { Tempo de } \\
\text { ignição (s) }\end{array}$ \\
\hline 1 & 7,3 & 2,63 & 1,8 & 12,5 & 2,58 & 0,0 \\
\hline 2 & 8,8 & 2,68 & 0,0 & 6,6 & 2,12 & 0,9 \\
\hline 3 & 4,2 & 2,50 & 30,3 & 8,3 & 2,15 & 89,4 \\
\hline 4 & 7,7 & 2,40 & 34,7 & 8,8 & 2,09 & 28,6 \\
\hline 5 & 8,1 & 2,56 & 0,9 & 7,0 & 2,17 & 0,0 \\
\hline
\end{tabular}

A variação da temperatura do forno pode ser explicada pelo mecanismo de transferência de calor, pelo qual após a inclusão de um material com temperatura ambiente em um forno a $750^{\circ} \mathrm{C}$ ocorre os mecanismos de radiação e de convecção com maior rapidez. A capacidade do material de absorver calor influencia no tempo para o mecanismo ser concluído como um todo, ou seja, a medida que a temperatura 
do material se aproxima da constância, a transferência de calor ocorre com menor intensidade até todos corpos estiverem com a mesma temperatura. Esta alteração da temperatura é calculada pela variação da temperatura máxima do forno, observada geralmente nos minutos inicias de ensaio, subtraída pela temperatura final do forno. Portanto, como nos ensaios foram observadas variações menores que $30^{\circ} \mathrm{C}$, todos os corpos de prova se apresentaram próximos a constância de temperatura e com isso o material não influenciaria significativamente, frente a este parâmetro, no aumento das proporções de um incêndio.

Observou-se também, conforme as Tabelas 6 e 7, chamejamento durante tempo superior a 10 segundos em todas as amostras de concreto com borracha reciclada, independente do teor de substituição deste material. A média aritmética indica tempo de ignição de 42,18 segundos para BOR5\% e 85,64 segundos para BOR10\%. Este comportamento pode ser explicado pela ignição da borracha e a permanência da chama até a combustão completa da sua estrutura, visto que este elastômero possui propriedades homogêneas em toda sua seção.

Já para o concreto com inserção de fibra metálica, houve evidência de chamejamento durante tempo superior a 10 segundos em parte das amostras, sendo que a média aritmética apresenta tempo de ignição de 13,54 segundos para FIB0,5\% e 23,78 segundos para FIB1,5\%. O chamejamento foi observado apenas no entorno na fibra, de modo que após a combustão da superfície, extinguiu-se a chama. Este comportamento irregular pode ser influenciado pela presença de impurezas combustíveis na superfície da fibra, dado que as fibras de aço utilizadas são provenientes da reciclagem.

Foi constatado ainda que as amostras com BOR10\% apresentaram um aumento na variação da temperatura do forno e do tempo de ignição em comparação às amostras BOR5\%. Estes resultados estão relacionados e coerentes, de modo que ao aumentar a quantidade de borracha reciclada nas amostras, também se aumenta a liberação de calor durante a ignização.

A Tabela 8 indica as médias de perda de massa para os concretos não convencionais ensaiados. A perda de massa média em amostras de concreto com borracha reciclada é cerca de $50 \%$ superior à perda de massa média em amostras de concreto com fibra metálica reciclada.

Tabela 8. Perda de massa média dos concretos não convencionais.

\begin{tabular}{|c|c|c|c|c|}
\hline \multirow{2}{*}{ Amostra } & \multicolumn{4}{|c|}{ Perda de massa (\%) } \\
\cline { 2 - 5 } & BOR5\% & BOR10\% & FIB0,5\% & FIB1,5\% \\
\hline Média & 4,69 & 4,76 & 2,55 & 2,22 \\
\hline
\end{tabular}

Ao relacionar os dois teores de borracha, observa-se o aumento da perda de massa no concreto BOR $10 \%$ em relação ao BOR $5 \%$, porém sem diferença discrepante. O concreto FIB0,5\% apresentou maior perda de massa em comparação ao FIB1,5\%, supostamente devido a maior presença de resíduos combustíveis no teor de $0,5 \%$, porém ambos teores apresentaram resultados similares.

Observa-se que o concreto com adição de borracha apresentou maior perda de massa do que o concreto com fibra. Este resultado se deve à combustão total da borracha inserida no concreto, durante o ensaio a $750^{\circ} \mathrm{C}$, sendo que as reações de degradação da borracha triturada do pneu iniciam aproximadamente em $300^{\circ} \mathrm{C}$ (SCURACCHIO; WAKI; BRETAS, 2006). Já as fibras apresentaram combustão parcial, apenas de sua superfície, uma vez que as fibras de aço recicladas possuem temperatura de derretimento entre $1.369^{\circ} \mathrm{C}$ e $1.704{ }^{\circ} \mathrm{C}$ (EUROREC, 2018).

\subsection{Análise térmica do agregado de borracha reciclada}

A Figura 4 apresenta os resultados do ensaio de DTGA e DSC para a borracha, resíduo reciclado de pneu, empregada neste estudo. É possível verificar que a amostra tem o pico de perda de massa aos $381,09^{\circ} \mathrm{C}$, característico da borracha triturada do pneu. A partir desta temperatura de pico, a massa residual foi muito próxima de zero caracterizando a decomposição deste material. De forma similar, 
para o ensaio de fluxo de calor, foi possível verificar que o pico de liberação de calor ocorreu aos $374,78^{\circ} \mathrm{C}$, em concordância com o ensaio de termogravimetria.

Considerando a situação a que o material foi exposto no ensaio de não-combustibilidade, onde a temperatura inicial do forno era de $750^{\circ} \mathrm{C}$, é possível verificar que a medida que o calor é transferido para as camadas nucleares internas do corpo de prova, ocorre a degradação da borracha. Devido à alta temperatura do ensaio, a degradação da borracha irá ocorrer de qualquer forma dentro do corpo de prova. No entanto, a manifestação das características de combustibilidade será condicionada com a capacidade que a matriz de concreto tem de encapsular as partículas borracha, prevenindo a manifestação destas características.

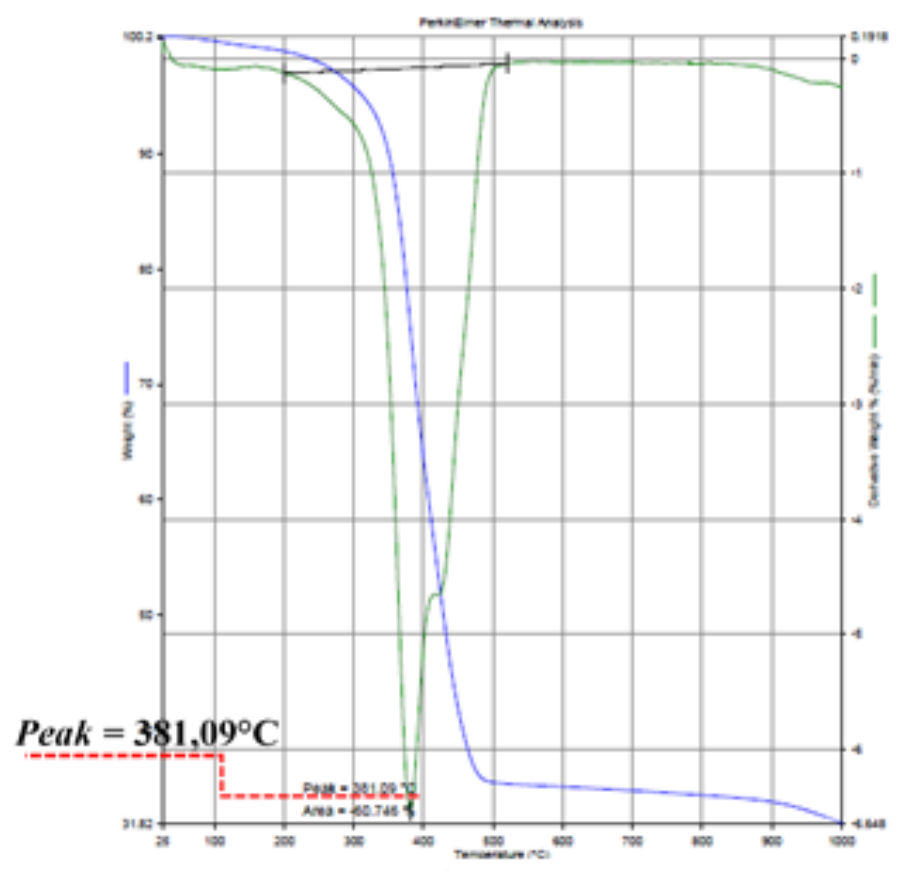

(a)

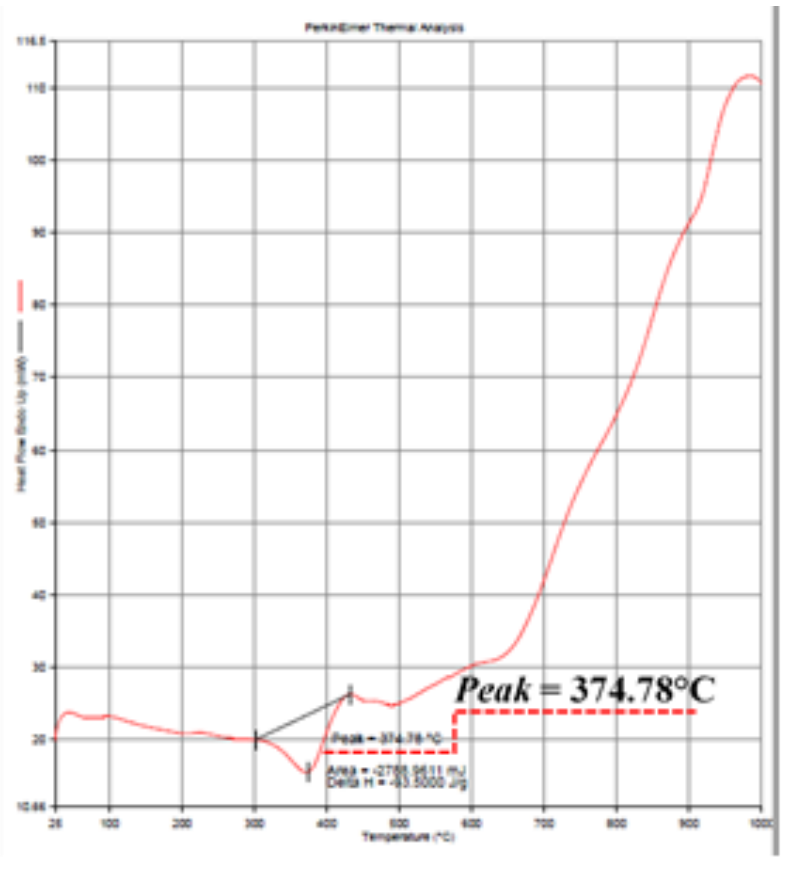

(b)

Figura 4. Gráfico do ensaio de (a) DTGA e (b) DSC da amostra de borracha oriunda do pneu.

\section{CONCLUSÕES}

O concreto convencional, conforme já esperado, é classificado de acordo com a NBR 16626 (ABNT, 2017) como não-combustível. Já os concretos com a utilização de resíduos de pneus inservíveis foram classificados, segundo a mesma normativa brasileira, como combustíveis. No entanto, a baixa perda de massa e pequena variação de na temperatura do forno observados na execução do ensaio são parâmetros favoráveis, pois são características que não influenciam significativamente no aumento dos danos em um incêndio.

O ensaio de não-combustibilidade é o primeiro ensaio relacionado à classificação de materiais de construção frente a altas temperaturas. Para os materiais classificados como combustíveis, faz-se necessário realizar outros ensaios visando avaliar propriedades específicas de liberação de calor, fumaça e propagação de chamas. Desta forma, o concreto com a utilização borracha e da fibra metálica recicladas de pneus inservíveis também devem ser ensaiados frente aos parâmetros de resistência ao fogo. 


\section{AGRADECIMENTOS}

Os autores gostariam de agradecer ao Instituto Tecnológico de Performance e Construção Civil (itt Performance), localizado na Universidade do Vale do Sinos (UNISINOS), pelo apoio a este estudo. Agradecimentos especiais à Concresul, INDIBA - Batistella Industrial de Artefatos de Borracha Ltda. e a Votorantim Cimentos pela doação de materiais.

\section{REFERENCIAS}

American Society for Testing and Materials (2018). ASTM E 662: Standard Test Method for Specific Optical Density of Smoke Generated by Solid Materials. West Conshohocken, Pennsylvania, USA. Associação Brasileira de Normas Técnicas (1988a). NBR 9442: Materiais de construção Determinação do índice de propagação superficial de chama pelo método do painel radiante - Método de ensaio. Rio de Janeiro.

Associação Brasileira de Normas Técnicas (1988b). NBR 9776: Agregados - Determinação da massa específica de agregados miúdos por meio do frasco chapman - Método de ensaio (cancelada). Rio de Janeiro.

Associação Brasileira de Normas Técnicas (2003). NBR NM 248: Agregados - Determinação da composição granulométrica. Rio de Janeiro.

Associação Brasileira de Normas Técnicas (2006). NBR NM 45: Agregados - Determinação da massa unitária e do volume de vazios. Rio de Janeiro.

Associação Brasileira de Normas Técnicas (2009a). NBR NM 52: Agregado miúdo - Determinação da massa específica e massa específica aparente. Rio de Janeiro.

Associação Brasileira de Normas Técnicas (2009b). NBR NM 53: Agregado graúdo - Determinação da massa específica, massa específica aparente e absorção de água. Rio de Janeiro.

Associação Brasileira de Normas Técnicas (2017). NBR 16626: Classificação da reação ao fogo de produtos de construção. Rio de Janeiro.

Eurorec: Environmetal Solutions for Waste Recycling (2018). Steel tire wire. Disponível em: <http://www.europeanrecycle.com/it/steelwire/steel-tire-wire/>. Acesso em: 22 maio.

International Organization for Standardization (2010). ISO 1182: Reaction to fire tests for products Non-combustibility test. Genebra.

Mitidieri, M. L.; Loshimoto, E. (1998), Proposta de classificação de materiais e componentes construtivos com relação ao comportamento frente ao fogo - Reação ao fogo. São Paulo: EPUSP.

Ono, R. (2007), Parâmetros para garantia da qualidade do projeto de segurança contra incêndio em edifícios altos. Ambiente Construído, v. 7, n. jan./mar., p. 97-113.

Pacheco, F. (2016). Investigação da relação entre os parâmetros de projeto das estruturas de concreto armado visando à durabilidade. 193 f. Dissertação (mestrado) - Universidade do Vale do Rio dos Sinos, Programa de Pós-Graduação em Engenharia Civil. São Leopoldo, RS, Brasil, 2016.

Pinto, A. R. M. et al. (2017), Gerenciamento de pneus inservíveis: estudo da reciclagem e destinação. Revista Meio Ambiente e Sustentabilidade, v. 10, p. 28-57.

Scuracchio, C. H.; Waki, D. A.; Bretas, R. E. S. (2006), Caracterização térmica e reológica de borracha de pneu desvulcanizada por microondas. Polímeros, v. 16, p. 46-52.

Silva Júnior, F. A. (2014). Avaliação do efeito da adição de resíduo de borracha de pneu e brita calcária na formulação de compósitos cimentíceos. $184 \mathrm{f}$. Tese (doutorado) - Universidade Federal do Rio Grande do Norte, Programa de Pós-graduação em Ciências e Engenharia de Materiais. Natal, RN, Brasil, 2014. 